\title{
A limited effect of sub-tropical typhoons on phytoplankton dynamics
}

\author{
Fei Chai ${ }^{1,2}$, Yuntao Wang ${ }^{1}$, Xiaogang Xing ${ }^{1}$, Yunwei Yan ${ }^{1}$, Huijie Xue ${ }^{2,3}$, Mark Wells ${ }^{2}$, and Emmanuel Boss ${ }^{2}$ \\ ${ }^{1}$ State Key Laboratory of Satellite Ocean Environment Dynamics, Second Institute of Oceanography, \\ Ministry of Natural Resources, Hangzhou 310012, China \\ ${ }^{2}$ School of Marine Sciences, University of Maine, Orono, ME 04469, USA \\ ${ }^{3}$ State Key Laboratory of Tropical Oceanography, South China Sea Institute of Oceanology, \\ Chinese Academy of Sciences, Guangzhou 510301, China
}

Correspondence: Fei Chai (fchai@maine.edu) and Yuntao Wang (yuntao.wang@sio.org.cn)

Received: 10 August 2020 - Discussion started: 27 August 2020

Revised: 3 December 2020 - Accepted: 15 December 2020 - Published: 5 February 2021

\begin{abstract}
Typhoons are assumed to stimulate primary ocean production through the upward mixing of nutrients into the ocean surface. This assumption is based largely on observations of increased surface chlorophyll concentrations following the passage of typhoons. This surface chlorophyll enhancement, occasionally detected by satellites, is often undetected due to intense cloud coverage. Daily data from a BGC-Argo profiling float revealed the upper-ocean response to Typhoon Trami in the northwest Pacific Ocean. Temperature and chlorophyll changed rapidly, with a significant drop in sea surface temperature and a surge in surface chlorophyll associated with strong vertical mixing, which was only partially captured by satellite observations. However, no net increase in vertically integrated chlorophyll was observed during Typhoon Trami or in its wake. In contrast to the prevailing dogma, the result shows that typhoons likely have a limited effect on net primary ocean production. Observed surface chlorophyll enhancements during and immediately following typhoons in tropical and subtropical waters are more likely to be associated with surface entrainment of deep chlorophyll maxima. Moreover, the findings demonstrate that remote sensing data alone can overestimate the impact of storms on primary production in all oceans. Full understanding of the impact of storms on upper-ocean productivity can only be achieved with ocean-observing robots dedicated to high-resolution temporal sampling in the path of storms.
\end{abstract}

\section{Introduction}

The western North Pacific Ocean is a highly energetic region on the globe (Gray, 1968) and is where nearly onethird of tropical cyclones originate (Needham et al., 2015). The strong tropical cyclones in this region, referred to as typhoons, are highly dangerous and have caused great loss of life and property throughout history (Frank and Husain, 1971; Dunnavan and Diercks, 1980; Kang et al., 2009; Needham et al., 2015). Typhoons extract their energy from warm surface ocean waters; thus the heat content in the upper ocean (quantified by the sea surface temperature (SST) as the indicator) has a key role in development of typhoons (Emanuel, 1999). Increasing SST in the North Pacific over the past few decades (He and Soden, 2015) coincides with an increase in the number of intense typhoons in the region (Emanuel, 2005; Webster et al., 2005; Vecchi and Soden, 2007; Kossin, 2018), which has been found to relate to climate change (Mei et al., 2015). The trend draws public attention for its potential influence on increasing climate extremes in this region.

Numerous studies have analyzed the impact of typhoons on upper-ocean conditions (e.g., Sun et al., 2010; Zhang et al., 2018). Higher surface ocean temperatures enhance stratification and thus decrease the nutrient flux, which reduces the ability of typhoons to cool the upper ocean and to elevate the growth of phytoplankton (Zhao et al., 2017). Ocean productivity and carbon sequestration are subsequently reduced, helping to sustain the continued global temperature increase (Balaguru et al., 2016). The high winds 
and strong energy exchange associated with typhoons (Price, 1981), on the other hand, are suggested to partially reverse this trend by mixing subsurface cold and nutrient-rich water into the sunlit surface layer (Babin et al., 2004). This results in decreasing SST and enhanced phytoplankton growth at the ocean surface (Platt, 1986; Ye et al., 2013).

The feedback from ocean to typhoon, on the other hand, is important for the development and maintenance of typhoons, as typhoons require extracting energy from the ocean surface (Zheng et al., 2008). The translation speed, e.g., the moving speed of a typhoon, plays an important role in determining the interaction between the ocean surface and typhoon (Pothapakula et al., 2017). The typhoon can lose energy and become weak when passing over a cold surface, such as regions cooled by the typhoon itself; thus, slowly moving typhoons can hardly develop into stronger storms (Lin et al., 2009). On the other hand, the longer a typhoon lingers around a certain location the stronger its local impact (Zhao et al., 2008); the resulting cooling effect further dampens the intensity of the typhoon. Thus, strong typhoons in midlatitude regions are generally characterized as fast-moving typhoons (Lin, 2012).

As typhoons propagate, they can drive substantial vertical mixing in the upper ocean (Han et al., 2012). Typhooninduced mixing lasts for approximately 1 week with an impact from the surface to as deep as $100 \mathrm{~m}$ (Price et al., 1994). Mixing acts to deepen the mixed-layer depth (MLD), resulting in a redistribution of ocean surface parameters (Lin et al., 2017). For typhoons passing over regions with shallow water depth and strong stratification, large ocean surface responses are generally observed (Zhao et al., 2017). At the same time, the typhoon-driven upwelling via the wind stress curl is found to influence depths of $200 \mathrm{~m}$ or more (Zhang et al., 2018). The relative impact of mixing and upwelling has been compared in many former studies, though their conclusions largely vary. For example, mixing is reported to be much more effective for inducing ocean surface changes compared to upwelling (Jacob et al., 2000). Lin et al. (2017) compiled the impacts of tropical cyclones for the upper $1000 \mathrm{~m}$ in the northwest Pacific and found that the contribution of mixing is dominant only in the surface layer that is shallower than $35 \mathrm{~m}$.

There is a strong linkage among the stratification in the upper ocean, chlorophyll distribution and nutricline in midlatitude regions, where any intensification of vertical mixing often leads to a surge in nutrient flux to surface waters. However, the same linkage is not necessarily true in tropical and subtropical regions, where a two-stratum sunlit "surface" layer forms. Here, the wind-mixed layer comprises only the upper (shallow) portion of the sunlit and nutrient-depleted surface layer, with the former being much shallower than the latter (Du et al., 2017). In this case, the photic zone extends far below the typical wind-mixed layer, and a deep chlorophyll maximum (DCM) forms at the top of the nutricline and may exist at twice the depth of the wind-mixed layer or deeper (Letelier et al., 2004; Cullen 2015; Gong et al., 2017; Pan et al., 2017). The question then is whether the energy transfer from typhoons generates sufficient mixing to "break" through both the base of the wind-mixed layer and the deeper nutricline, thereby transferring new nutrients into the photic zone. Typhoon-induced upwelling can transport nutrient-enriched waters into the photic zone and has been shown to enhance subsurface chlorophyll concentrations in the South China Sea (Ye et al., 2013). However, the question remains whether similar processes will occur for the subtropical oceans where the nutricline is much deeper.

In addition to the intensive wind field, typhoons are also associated with intensified rainfall and cloud cover (Liu et al., 2013), which can substantially contaminate satellite observations. Satellite-based studies occasionally capture the ocean surface features during the passage of a typhoon and offer more data in the wake following typhoons (Chang et al., 2008). Remote sensing data revealed that the SST rapidly decreases during typhoon passage, whereas chlorophyll can increase afterwards (Chen and Tang, 2012; Zhao et al., 2017). It was suggested that the delayed response of surface chlorophyll is related to the time needed for phytoplankton to exploit the increased nutrient concentrations and accumulate (Chen et al., 2014). The time for phytoplankton growth depends on the phytoplankton species, e.g., at least $3 \mathrm{~d}$ and $5 \mathrm{~d}$ are respectively required for diatoms and small phytoplankton to accumulate significantly after nutrient infusion (Pan et al., 2017).

Typhoon-induced ocean responses largely vary in intensity and even in magnitude of changes depending on the typhoon's features and pre-typhoon ocean state. Slow, strong typhoons appear to be favorable for inducing an oceanic response (Lin et al., 2017), which can be amplified by preexisting cyclonic eddies (Sun et al., 2010). Bauer and Waniek (2013) showed that individual typhoons may more than double the surface phytoplankton biomass, though subsurface effects could not be quantified. On the other hand, Zhao et al. $(2008,2017)$ found that only strong and slow-moving typhoons impart sufficient energy to increase surface chlorophyll concentrations. The diverse outcomes observed among typhoons and upper-ocean interactions (Chang et al., 2008; Chen and Tang, 2012; Balaguru et al., 2016), weighted heavily by surface-only satellite observations, illustrate the incomplete understanding of how typhoons may affect the primary productivity in the present and future ocean. In this study, the vertical sections obtained with a biogeochemicalArgo (BGC-Argo) profiling float are used to describe the entire upper-ocean response to the passage of a strong typhoon in oceanic subtropical waters, offering novel insights that detangle the underlying physical and biological dynamics. 


\section{Methods}

\subsection{Data used in this study}

The BGC-Argo profiling float (ID: 2902750), an unmanned observational platform (Bishop et al., 2002; Boss et al., 2008; Claustre et al., 2010; Mignot et al., 2014; Chacko, 2017), was deployed by the State Key Laboratory of Satellite Ocean Environment Dynamics (SOED) of China in early September of 2018 in the northwest Pacific (south of Japan). It was equipped with a conductivity-temperature-depth (CTD) instrument (SBE41CP manufactured by Seabird) measuring temperature and salinity and an optical sensor package (ECO Triplet manufactured by WET Labs) measuring chlorophyll $a$ concentration ( $\mathrm{chl} a ; \mathrm{mg} \mathrm{m}^{-3}$ ), fluorescent dissolved organic matter (FDOM) and particulate backscattering coefficient (bbp; $\mathrm{m}^{-1}$ ). Measurements were made every night (around 22:00 LT) to avoid in vivo fluorescence nonphotochemical quenching. Vertical resolution of measurements was $\sim 1 \mathrm{~m}$ in the upper $1000 \mathrm{~m}$.

Float data were quality controlled following the requirement of the BGC-Argo program (Schmechtig et al., 2016) before uploading to the Argo Global Data Assembly Center (GDAC). Data used in this study are available from the Coriolis GDAC FTP server (Argo, 2020). Chl $a$ and bbp (700) sections were smoothed with a five-point median filter, and their factory-calibrated dark counts for backscattering and Fchl (48 and 48, respectively) were replaced by the on-floatmeasured counts (50 and 53), which were measured by the sensors on the float before deployment.

The remote sensing observations of SST and sea surface chlorophyll (SSC) were obtained as the MODIS L3 data on board NASA's EOS Aqua satellite. Daily observations with global coverage were available from September 2002 until now. The spatial resolution was $1 / 24^{\circ}$, and there were no data present over land or cloud. Satellite-observed information near BGC-Argo was calculated by spatially averaging over a surrounding circle with a radius of $300 \mathrm{~km}$ following Wang (2020), excluding areas within $10 \mathrm{~km}$ of land.

Climatological information for the regions was obtained from the World Ocean Atlas (WOA) at a spatial resolution of $1^{\circ}$ (Locarnini et al., 2018). The data had an original 57 layers from the surface to $1500 \mathrm{~m}$ depth, and they were interpolated to $1 \mathrm{~m}$ vertical resolution beforehand. A monthly dataset of the temperature profile was subsequently used to delineate the climatological MLD, and the calculation will be described in the following section.

The typhoon information is obtained from the Japan Meteorological Agency (JMA, http://www.jma.go.jp/jma/ indexe.html, last access: 31 October 2018). The data include the maximum sustained wind (MSW), category and location (longitude and latitude) of the typhoon center every $6 \mathrm{~h}$. The category is defined based on the MSW, and the maximum MSW for the studied typhoon is 105 knots (approximately $54 \mathrm{~m} \mathrm{~s}^{-1}$ ), which is classi- fied as "class-5 violent typhoon" for the intensity class (agora.ex.nii.ac.jp/digital-typhoon/help/unit.html.en, last access: 30 November 2018) and category 3 with the SaffirSimpson scale (www.nhc.noaa.gov/aboutsshws.php, last access: 30 November 2018). The translation speed of the typhoon was calculated as the ratio between the spatial distance traveled between two successive typhoon centers in the $6 \mathrm{~h}$ time span.

\subsection{MLD and mixing-induced changes in temperature and chlorophyll}

Following Kara et al. (2000), the estimate of MLD was obtained using a density-based criterion with the increase in density equivalent to the decrease in temperature by $0.8^{\circ} \mathrm{C}$ from the ocean surface. The mixed-layer temperature (MLT) and mixed-layer chlorophyll (MLC) quantify the typhooninduced changes at daily intervals. The calculation correctly reflected the ocean turbulence mixing, where the MLT and MLC were simply the vertically averaged temperature and chlorophyll concentration from the surface to the MLD. We further defined and calculated the mixing-induced change in MLT in a daily interval using the following Eq. (1):

$$
\begin{aligned}
\Delta \mathrm{MLT}_{\mathrm{m}} & =\frac{\int_{0}^{h} \rho_{\mathrm{r}} C_{p} T_{0} \mathrm{~d} z}{\rho_{\mathrm{r}} C_{p} h}-\frac{\int_{0}^{h_{0}} \rho_{\mathrm{r}} C_{p} T_{0} \mathrm{~d} z}{\rho_{\mathrm{r}} C_{p} h_{0}} \\
& =\frac{\int_{0}^{h} T_{0} \mathrm{~d} z}{h}-\frac{\int_{0}^{h_{0}} T_{0} \mathrm{~d} z}{h_{0}},
\end{aligned}
$$

where $\Delta \mathrm{MLT}_{\mathrm{m}}$ is the mixing-induced change in MLT, $\rho_{\mathrm{r}}$ is the relative water density, $C_{p}$ is the specific heat capacity at constant pressure, $h$ is the MLD, and $h_{0}$ and $T_{0}$ are, respectively, the MLD and temperature from the previous day. The mixing-induced change in MLC was calculated similarly.

\section{Results}

The typhoon Trami was spawned in the tropical western Pacific in late September 2018 and moved from the tropics to the midlatitudes around Japan with an overall translation speed of $6.1 \pm 6.5 \mathrm{~m} \mathrm{~s}^{-1}$ (Fig. 1). The daily averaged translation speed was $19.3 \pm 6.1 \mathrm{~m} \mathrm{~s}^{-1}$ on 30 September, indicating that the typhoon was moving faster compared with other times in its lifespan. On this day, typhoon Trami passed over the BGC-Argo float with an average wind speed of $44 \mathrm{~m} \mathrm{~s}^{-1}$, and the shortest distance between the typhoon and the float was less than $100 \mathrm{~km}$. As the float drifted with the ocean circulation, its position changed slightly during the study period. In particular, the float was located at $30^{\circ} \mathrm{N}, 133.1^{\circ} \mathrm{E}$ on 25 September; $30.6^{\circ} \mathrm{N}, 133^{\circ} \mathrm{E}$ on 30 September; and $31.4^{\circ} \mathrm{N}, 133.6^{\circ} \mathrm{E}$ on 5 October. The zonal movement is not prominent, but the meridional shift is approximately $150 \mathrm{~km}$ northward. The climatological MLDs for BGC-Argo locations are 28, 41 and $60 \mathrm{~m}$ at approximately $30^{\circ} \mathrm{N}$ during August, September and October, respectively, and these values 
change to 30,46 and $66 \mathrm{~m}$ at approximately $31^{\circ} \mathrm{N}$, indicating a slight deepening towards the north.

The float depth vs. time property sections, consistent with remote sensing data of surface properties, show a rapid drop in surface water temperatures above the base of the MLD and warming below it, which is associated with a swift deepening of the mixed layer upon passage of the typhoon (Fig. 2a and c). The largest reduction in SST $\left(>1^{\circ} \mathrm{C}\right)$ happened simultaneously with the arrival of the typhoon, consistent with the local shear-driven vertical mixing mechanism (Sriver and Huber, 2007; Chang et al., 2008; Zhao et al., 2008; Sanford et al., 2011).

The changes in the vertical distribution of chlorophyll were equally striking, with the chlorophyll concentration in the DCM decreasing from 0.8 to $0.4 \mathrm{mg} \mathrm{m}^{-3}$, while nearsurface values more than doubled (Fig. $2 b$ and d). We observed two surface chlorophyll peak values on 30 September and 3 October, at 0.18 and $0.15 \mathrm{mg} \mathrm{m}^{-3}$, respectively. These increases represent changes of 0.13 and $0.1 \mathrm{mg} \mathrm{m}^{-3}$, respectively, above the concentration measured on 29 September before the typhoon approached the area. The highest value occurred on 30 September when the surface wind peaked around the BGC-Argo float, which supports the vertical mixing mechanism. This enhancement was, however, not captured by satellite remote sensing due to intense cloud cover from the typhoon.

Vertical mixing appeared to be the dominant physical process during the typhoon Trami passage. The MLD deepened dramatically from $40 \mathrm{~m}$ before 29 September to $94 \mathrm{~m}$ as the wind speed peaked on 30 September (Fig. 3a). While the MLT decreased quickly, the integrated ocean heat content $(\mathrm{OHC})$ of the top $150 \mathrm{~m}$ remained relatively constant at approximately $1.47 \mathrm{~J} \mathrm{~m}^{-2}$ (Fig. 3b), suggesting that upwelling was minimal. The elevated MLC coincided with decreasing concentrations at DCM (Fig. 3c). As a consequence, the strong vertical mixing generated no increase in the depthintegrated chlorophyll within the upper $150 \mathrm{~m}$ either during or after the passage of Typhoon Trami (Fig. 3d). There was no increase measured in particle backscatter coefficient (bbp) that correlates well with phytoplankton carbon (Graff et al., 2015), suggesting there was no significant change in phytoplankton abundance or any shift towards larger phytoplankton that might enhance carbon export.

The temperature above $50 \mathrm{~m}$ decreased with the largest reduction near the surface, while the temperature beneath increased simultaneously (Fig. 4a). This process was fully captured as Trami approached until $6 \mathrm{~d}$ after its passing. The largest temperature increase happened between 75 and $100 \mathrm{~m}$ from 30 September to 3 October when the surface temperature dropped prominently, which indicated the heat exchange between the upper and lower regions of the photic zone. Consistently, the time series of chlorophyll sections depict the typhoon-induced chlorophyll enhancement near the surface and decrease below (Fig. 4b). Because the initial vertical gradient of chlorophyll was very low in the upper $50 \mathrm{~m}$, the increase was mainly uniform throughout the upper $50 \mathrm{~m}$. The largest decrease in chlorophyll was observed at approximately $110 \mathrm{~m}$ depth where the initial DCM was located. This pattern is consistent with that from shipboard observations after another typhoon event where a strong vertical movement of particles occurred in the subsurface layer rather than at the surface (Ye et al., 2013). Interestingly, both the temperature and chlorophyll increased in the subsurface, e.g., between 50 and $100 \mathrm{~m}$, during the week before the arrival of the typhoon, presumably due to the seasonal cycle of MLD that is deepening in the study period, associated with increasing winds in front of the typhoon path (Fig. 3a).

We calculated the mixing-induced daily change in mixedlayer temperature and chlorophyll $\left(\triangle \mathrm{MLT}_{\mathrm{m}}\right.$ and $\triangle \mathrm{MLC}_{\mathrm{m}}$; see the definition in the Methods section) and compared them with the daily change in SST and SSC from the BGC-Argo float data ( $\triangle \mathrm{SST}$ and $\Delta \mathrm{SSC}$ ) (Fig. 4c). A good agreement can be found between the mixing-induced difference and the actual change. Thus, the observed surface change in temperature was predominantly attributed to strong wind mixing during typhoon passage. The calculated $\Delta \mathrm{MLT}_{\mathrm{m}}$ of $1.8^{\circ} \mathrm{C}$ on 30 September was similar to the value of $\Delta \mathrm{SST}$ and consistent with the strong mixing scenario. Similarly, there was close agreement between the observed SSC and calculated $\triangle \mathrm{MLC}_{\mathrm{m}}$ that matched the peak on 30 September, which indicates that strong vertical mixing contributes to the surface chlorophyll increase.

\section{Discussion}

The passage of a typhoon over the float offers a unique opportunity to fully resolve typhoon-induced oceanic responses throughout the upper water column. In contrast to the interpretation of remote sensing data, super-typhoon Trami did not significantly boost phytoplankton biomass or production in the upper ocean. The measured increases in near-surface chlorophyll concentrations resulted simply from the redistribution of phytoplankton, originally residing in the deep chlorophyll maximum, across the mixed layer now reaching throughout the photic zone, as summarized in Fig. 5. This finding implies that using satellite observations alone would overestimate typhoon-induced changes in primary production unless consideration is given to chlorophyll redistribution in the water column.

Typhoon-induced mixing dominated the variability of surface chlorophyll during the passage of Trami, which led to the redistribution of chlorophyll within the upper ocean (Fig. 3c). In many former remote sensing studies, typhoons were thought to boost primary production by transporting nutrients across the nutricline into the photic zone (e.g., Chen and Tang, 2012), and the peak of chlorophyll is typically reached a few days after the minimum SST because time is required for the accumulation of phytoplankton (Shang et al., 2008). However, the high-frequency in situ float profil- 

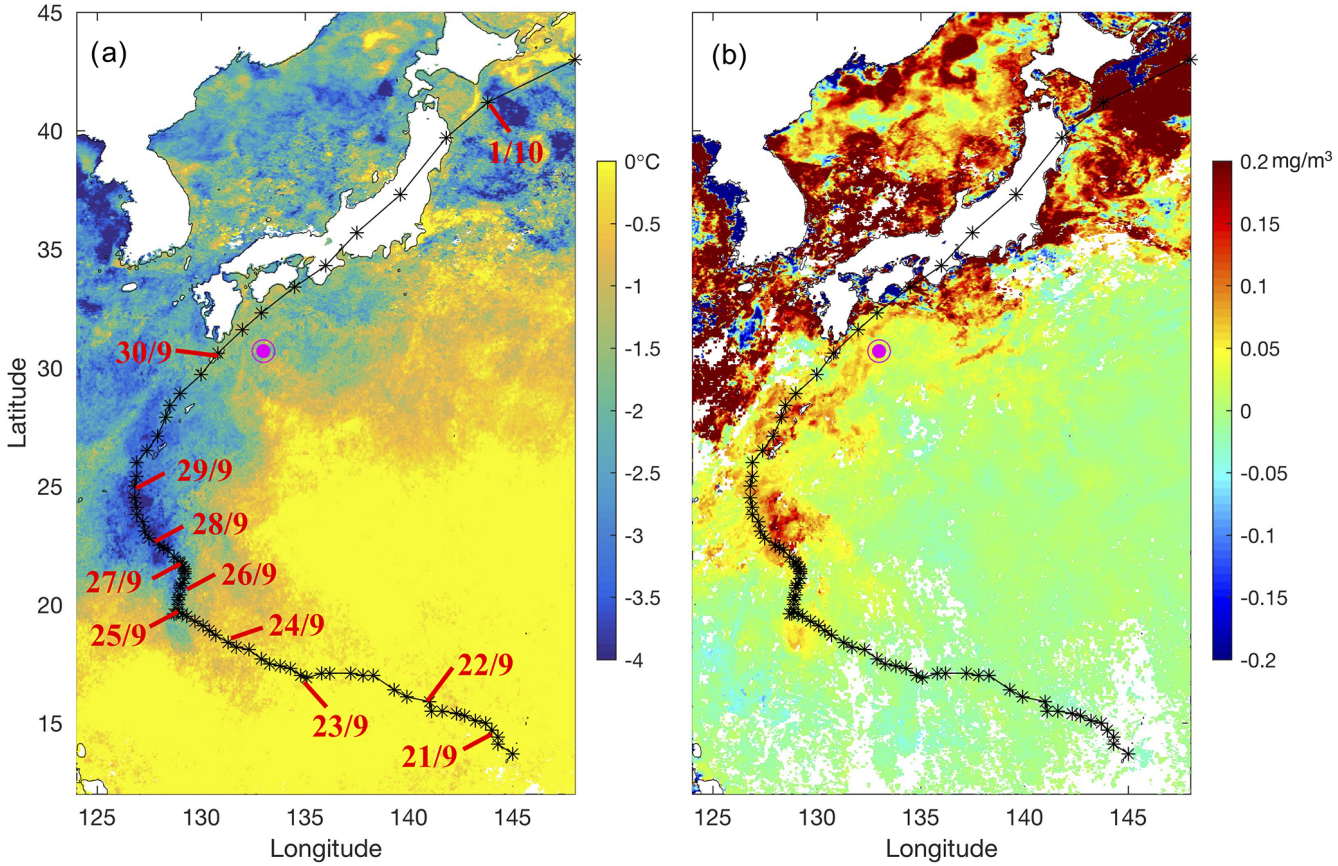

Figure 1. The differences in averaged sea surface temperature (a) and chlorophyll (b) measured during the period from 10 to 30 September vs. that measured from 1 to 20 October. The remote sensing observations were obtained as the MODIS L3 daily data. The trajectory of Typhoon Trami is shown as a black curve with its central location every $3 \mathrm{~h}$ labeled as asterisks and the date labeled for the location at noon (UTC). The location of the Biogeochemical Argo (BGC-Argo) float on 30 September is shown as a magenta symbol.
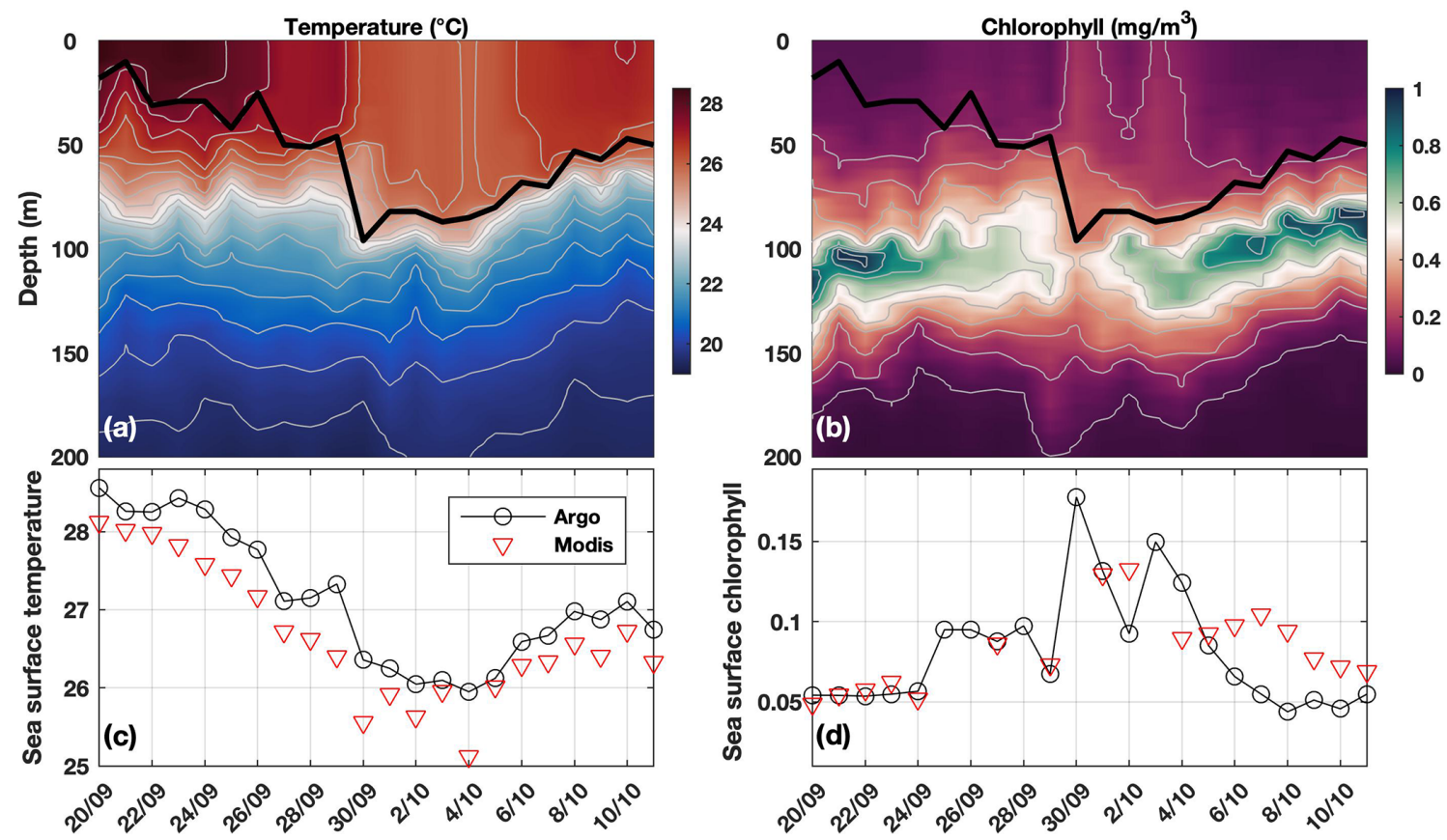

Figure 2. Sections of temperature (a) and chlorophyll (b) captured by the BGC-Argo; superimposed as the thick black curve is the mixedlayer depth (MLD). Comparison between the sea surface temperature (c) and chlorophyll (d) from the BGC-Argo and remote sensing observations. Typhoon Trami passed nearby BGC-Argo on 30 September 2018. 

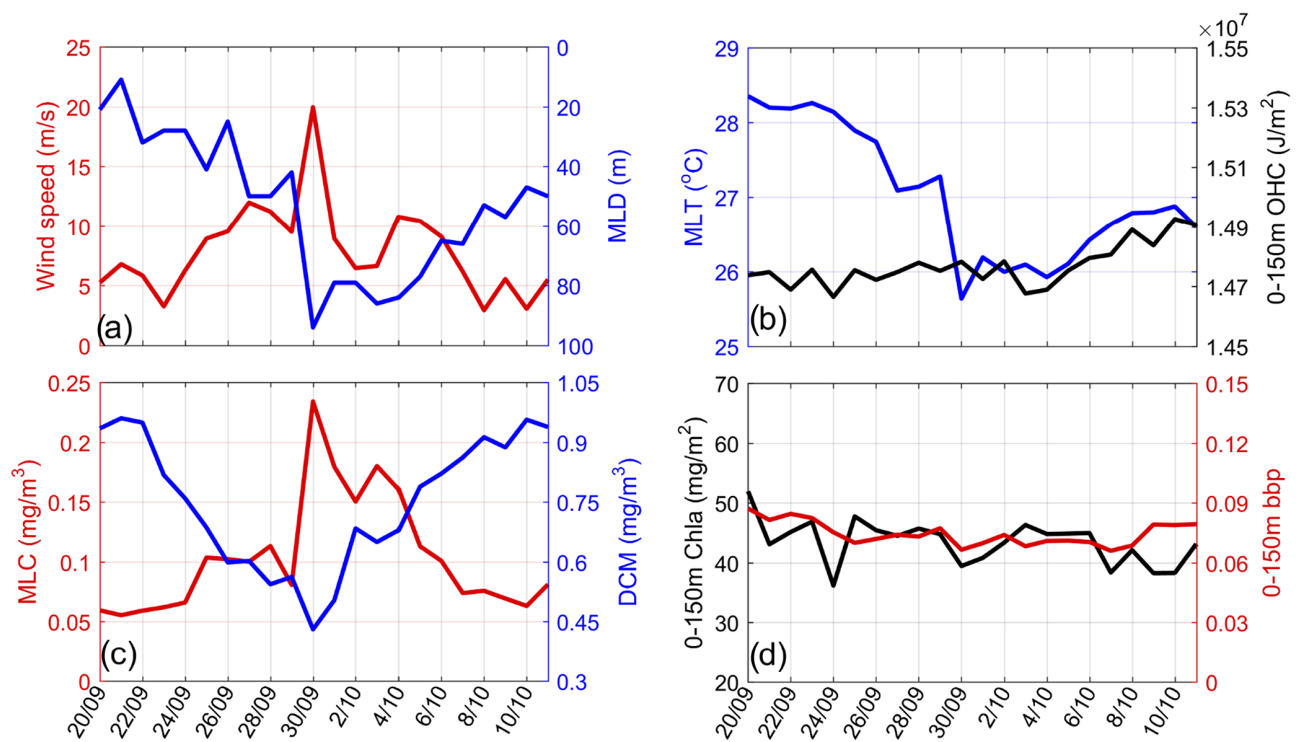

Figure 3. Time series of (a) the wind speed and MLD at BGC-Argo, (b) mean temperature above the MLD (MLT) and integrated ocean heat content $(\mathrm{OHC}$ ) between 0 and $150 \mathrm{~m}$, (c) mean chlorophyll above the MLD (MLC) and deep chlorophyll maximum (DCM), and (d) integrated chlorophyll and bbp between 0 and $150 \mathrm{~m}$.
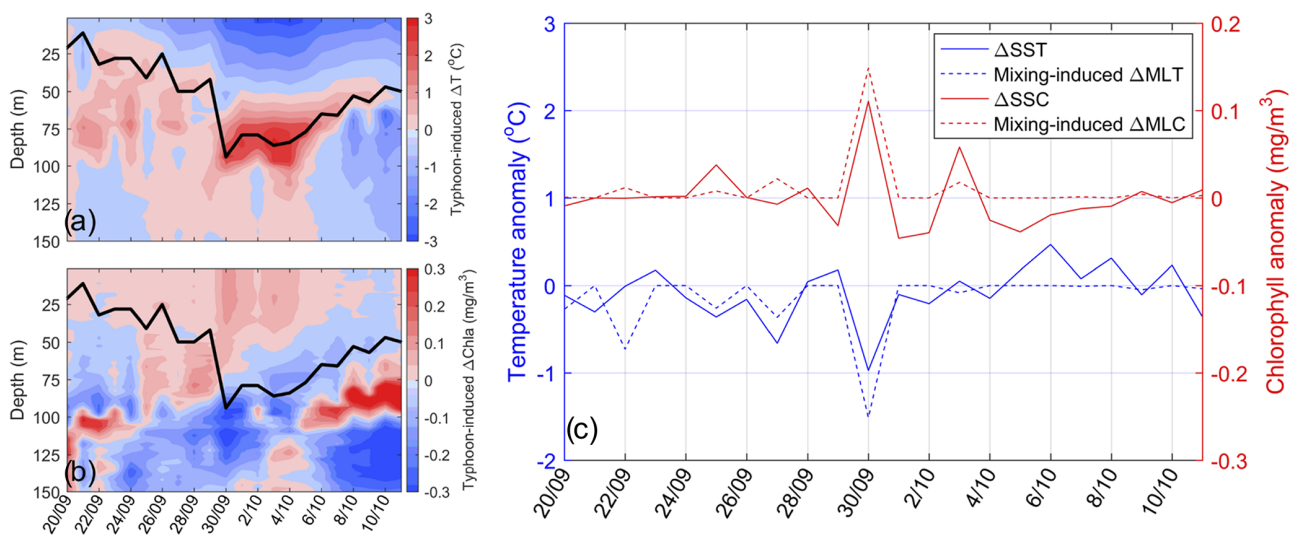

Figure 4. Sections of typhoon-induced changes in (a) temperature and (b) chlorophyll concentration. The changes were calculated for each day's section by subtracting the averaged section from $7 \mathrm{~d}$ prior to 20 September (i.e., 13 to 19 September). (c) Time series of the change in sea surface temperature ( $\triangle \mathrm{SST}$, solid blue), mixing-induced change in the MLT (dashed blue), sea surface chlorophyll concentration ( $\Delta \mathrm{SSC}$, solid red) and mixing-induced change in the MLC (dashed red).

ing here shows almost no changes in integrated temperature and chlorophyll concentration over the top $150 \mathrm{~m}$ (Fig. 3d). Indeed, the upward displacement of the isotherm is only observed for the upper ocean shallower than $100 \mathrm{~m}$ (Fig. 2a), whereas upwelling is usually found throughout the water column extending more than $200 \mathrm{~m}$ (Lin et al., 2017). The results differ from those observed closer to shore in the South China Sea where the pycnocline is much shallower and thus more susceptible to becoming incorporated into the windmixed layer (Ye et al., 2013), and they indicate that mixing is much stronger than upwelling. The outcomes suggest the importance of comparing typhoon-induced mixing depth, thermocline and nutricline when discussing the upper ocean's re- sponses to typhoons. Similarly, stronger typhoon-induced responses are found in pre-existing cyclonic eddies where nutricline is elevated by upwelling (Zheng et al., 2008; Wu and $\mathrm{Li}, 2018$ ). A net decrease in heat content and increase in primary production can only be achieved if typhoons penetrate the thermocline and nutricline, respectively (Zhang et al., 2018).

As the mixing process dominated the dynamics in ocean surface, the impact of Typhoon Trami occurs and fades quickly during and after the typhoon, respectively (Fig. 2d). Surface chlorophyll concentration usually relaxed to its initial value within the next few days, even weeks, after the typhoon, which was formerly attributed to the consumption 


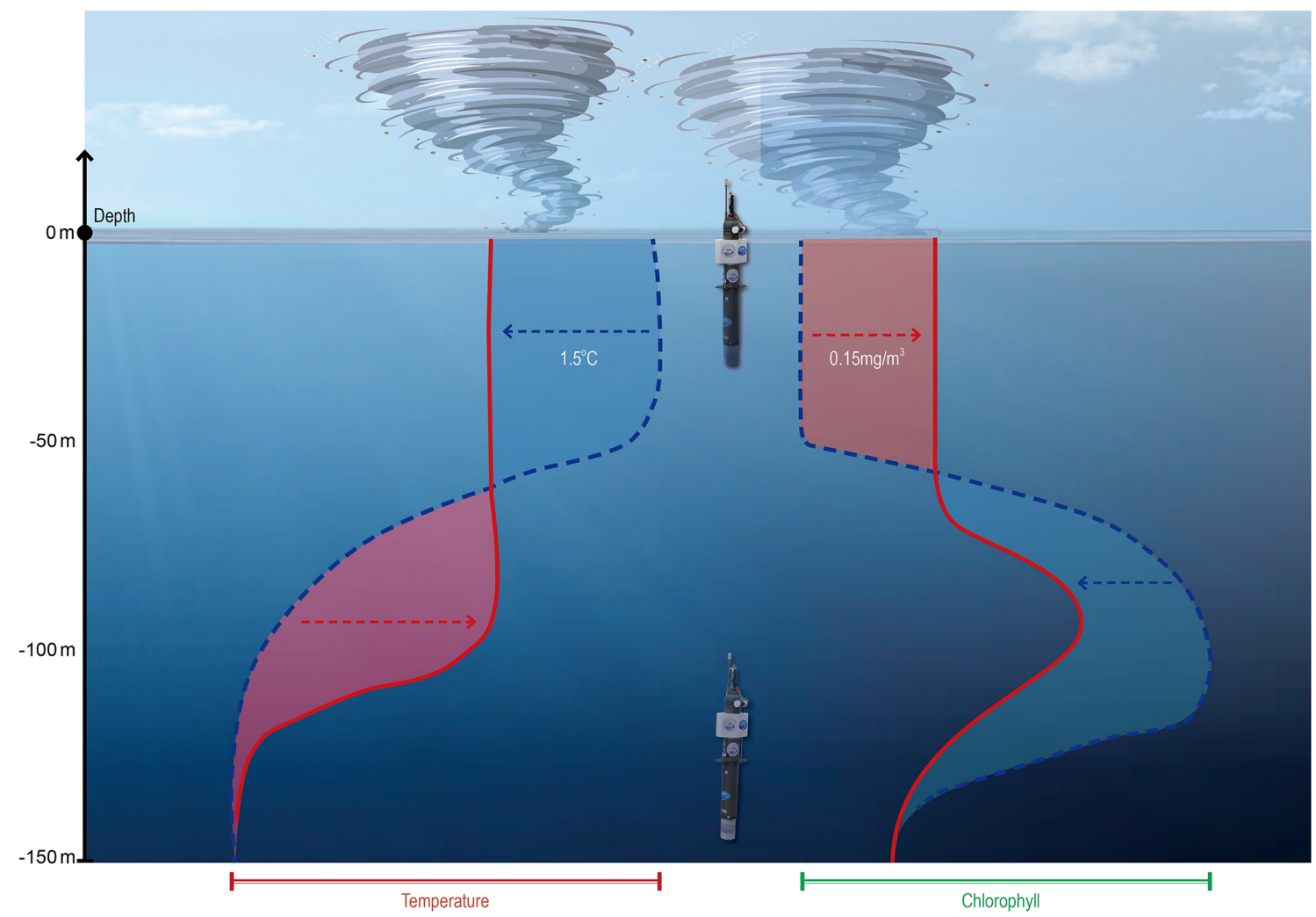

Figure 5. Schematic diagram for a typhoon's impact on the vertical distribution of temperature (left) and chlorophyll (right). Blue dashed (red solid) lines correspond to vertical profiles before (after) a typhoon; blue and red dashed arrows mean decrement and increment, respectively, of temperature and chlorophyll.

of nutrients (Shibano et al., 2011) and grazing (Zhou et al., 2011; Chung et al., 2012). Conversely, chlorophyll biomass rapidly fades in the next $5 \mathrm{~d}$ at the surface and increases quickly at depth to reestablish the DCM (Fig. 2b), indicating grazing would have played a greater role at the surface given the new nutrient inputs would have been minimal. By comparison, surface water temperature rose slowly, associated with the gradual shoaling of the MLD and increasing stratification (Fig. 2a). This is attributed to weaker solar radiation in the Trami typhoon region compared to stronger tropical solar radiation, which allows the SST and stratification to rebound quickly after passage of a typhoon (Gierach and Subrahmanyam, 2008).

The location of the float is approximately $200 \mathrm{~km}$ away from land, so it is unlikely that typhoon-induced rainfall on shore might have increased terrestrial nutrient fluxes sufficiently to influence the growth of phytoplankton (Zheng and Tang, 2007). Though typhoon-induced surface advection can extend southward from the coast of Japan for more than $100 \mathrm{~km}$ (Yang et al., 2010), there is not a significant trend in satellite-derived chlorophyll concentrations across the 10$300 \mathrm{~km}$ range from land (Fig. 1). The terrestrial impact induced by intensive rainfall is not prominent for the region around the float, which is different from other regions with estuaries, e.g., Pearl River estuary, where the rainfall associated with a typhoon can substantially increase nutrient concentration in the nearshore region (Zheng and Tang, 2007).

Typhoon Trami is characterized as a strong and fastmoving typhoon with large wind intensity and translation speed (Wu and $\mathrm{Li}, 2018$ ), which are favorable for inducing prominent changes in surface ocean processes (Pothapakula et al., 2017). There was almost no lingering during its propagation, and the self-induced cooling did not largely impact the typhoon intensity (Glenn et al., 2016). Indeed, the ocean surface cooling and bloom were particularly intense along the right-hand side of the typhoon track where the float was located (Fig. 1a). The right side of typhoons are often believed to be subject to more energetic mixing (e.g., Babin et al., 2004), although Huang and Oey (2015) showed only weak asymmetry in mixing across storms.

The typhoon-induced oceanic response was observed in a relatively short period (e.g., the rapid change happened within a few days and the recovery took a few weeks; Fig. 4) but the associated large-scale environmental changes should also be evaluated, especially the change induced by the drifting of the float. The MLD deepened during the period when the float drifted northward, though only a small distance, and followed the seasonal variation in MLD (not shown); thus, 
both the subsurface temperature and chlorophyll were elevated due to intensified mixing (Fig. 4a and b). Additionally, the wind stress increased before the arrival of the typhoon, resulting in ahead-of-eye cooling and mixing that has been shown to take place a few days earlier (Glenn et al., 2016; Wang, 2020).

The decrease in SST is a well-known phenomenon associated with typhoons; in comparison, the typhoon-induced variation in chlorophyll concentration is much more complex and varies by case. Increased chlorophyll concentrations are found in $70 \%$ of typhoons in the South China Sea (Wang, $2020)$ and $18 \%$ of typhoons in the northwest Pacific Ocean (Lin, 2012). These satellite-derived observations of increased surface chlorophyll may be due to enhanced nutrient flux into surface waters from either vertical mixing or enhanced upwelling reaching beyond the nutricline (Zhang et al., 2018), or as shown here, simply mixing of phytoplankton biomass in the DCM throughout the mixed layer (Fig. 2). Distinguishing among these mechanisms cannot be done by satellite observations alone, due to both the high cloud coverage associated with typhoons (Chen and Tang, 2012) and the limitation of sampling only the uppermost ocean surface. The novel float dataset here reveals an added complexity to understanding the progressive effects of typhoon intensity on surface water dynamics and phytoplankton production.

The findings here have a broad application for assessing the impact of typhoons on global primary production and carbon cycling (Menkes et al., 2016). A climate-driven increasing trend of super-typhoons (Elsner et al., 2008; Sobel et al., 2016) is likely to cause larger biogeochemical alterations in shelf and nearshore regions where nutricline is comparatively shallow, but they will be much less effective in boosting oceanic productivity in regions where the nutricline is deep and thus more sheltered from enhanced vertical transport. Re-examination of past storm events in this context would better quantify changes in primary production, but our findings imply that future increases in storm frequency alone are unlikely to mitigate the declining trend in global phytoplankton biomass resulting from the enhanced stratification due to warming (Boyce et al., 2010; Lin and Chan, 2015).

The standard float profiles every $5-10 \mathrm{~d}$ to extend its operational lifetime (Johnson and Claustre, 2016); this sampling frequency is too low to capture the daily or weekly variability induced by synoptic weather and other short-term events. Near-daily sampling frequencies, on the other hand, better inform on rapid processes in response to short-term atmospheric perturbations (Xing et al., 2020). Combined with high-frequency remote sensing data, these observations would enable the development of new and more comprehensive conceptual and quantitative models (Terzić et al., 2019) to improve our understanding of how climate drivers will influence ocean primary production and the associated carbon export in future oceans.

\section{Conclusions}

Observational datasets from daily BGC-Argo sections provide a unique opportunity to study the impact of typhoons on the upper-ocean structure and productivity in subtropical waters. The daily profiling frequency capture of the rapid response of the ocean surface to typhoon Trami and our findings show substantial increases in vertical mixing and surface phytoplankton biomass, similar to past studies. Unlike observations in nearshore regions with a shallower nutricline, upwelling contributed new nutrients into the photic layer and enhanced net growth of phytoplankton. In the current study, the results clearly showed that mixing overwhelmed the dynamics during the passage of typhoon Trami, while the impact of upwelling was much less pronounced. The observed surface phytoplankton bloom is actually attributed to mixing in the upper ocean, e.g., redistribution of the DCM throughout the mixed layer, generating no net increase in phytoplankton biomass. Satellite-based studies reporting delayed phytoplankton blooms in the wake of typhoons over oceanic waters, which infer subsurface nutrient infusion, may be biased by cloud cover obstructing surface observations during the passage of a typhoon. Our findings imply that previous assumptions have overestimated typhoon-enhanced phytoplankton production from mixing or upwelling transport of new nutrients into the photic zone and that much of this inferred new production instead is driven by vertical redistribution of existing biomass from the DCM. The findings here also provide a lesson on how cutting-edge observational platforms such as BGC-Argo floats can be adapted to resolve short-term, episodic events, delivering information that is not fully resolved by traditional observations. Automatically adapting systems, which change the sampling frequency based on the duration of targeted events (Chai et al., 2020), will be important for improving the understanding of weather and climate impacts on the marine system.

Data availability. The BGC-Argo float data used for this study can be downloaded from ftp://ftp.ifremer.fr/ifremer/argo (Argo, 2020, last access: 31 December 2018). Satellite observation files are available from the database of National Aeronautics and Space Administration (NASA) for SST (https://doi.org/10.5067/MODSA1D4D9, NASA OBPG, 2019, last access: 31 March 2019) and SSC (https://doi.org/10.5067/AQUA/MODIS/L3B/CHL/2018, NASA Goddard Space Flight Center, 2018, last access: 31 March 2019). The typhoon information was downloaded from the Best Track Data from the RSMC Tokyo - Typhoon Center at the Japan Meteorological Agency (JMA, http://www.jma.go.jp/jma/jma-eng/ jma-center/rsmc-hp-pub-eg/besttrack.html, last access: 31 October 2018).

Author contributions. FC designed the observational plan, interpreted the data and wrote the manuscript. YW organized the figures and results and worked on the draft. XX and YY conducted the 
data analysis. HX, MW and EB provided insightful comments and improved the manuscript.

Competing interests. The authors declare that they have no conflict of interest..

Special issue statement. This article is part of the special issue "Biogeochemistry in the BGC-Argo era: from process studies to ecosystem forecasts (BG/OS inter-journal SI)". It is not associated with a conference.

Acknowledgements. The authors appreciate Argo and the BGCArgo program, JMA and NASA for sharing the data. We are grateful to the Second Institute of Oceanography, Ministry of Natural Resources, China, for supporting the deployment and data processing of BGC-Argo.

Financial support. This research has been supported by the National Key Research and Development Program of China (grant no. 2016YFC1401600) and the National Natural Science Foundation of China (grant nos. 41730536 and 41890805).

Review statement. This paper was edited by Paolo Lazzari and reviewed by Peter Strutton, Waldemar Walczowski and one anonymous referee.

\section{References}

Argo: Argo float data and metadata from Global Data Assembly Centre (Argo GDAC), SEANOE, https://doi.org/10.17882/42182, 2020.

Babin, S. M., Carton, J. A., Dickey. T. D., and Wiggert, J. D.: Satellite evidence of hurricane induced phytoplankton blooms in an oceanic desert, J. Geophys. Res., 109, C03043, 2004.

Balaguru, K., Foltz, G. R., Leung, L. R., and Emanuel, K. A.: Global warming-induced upper-ocean freshening and the intensification of super typhoons, Nat. Commun., 7, 13670, 2016.

Bauer, A. and Waniek, J. J.: Factors affecting chlorophyll a concentration in the central Beibu Gulf, South China Sea, Mar. Ecol. Prog. Ser., 474, 67-88, 2013.

Bishop, J. K. B., Davis, R. E., and Sherman, J. T.: Robotic observations of dust storm enhancement of carbon biomass in the North Pacific, Science, 298, 817-821, 2002.

Boss, E., Swift, D., Taylor, L., Brickley, P., Zaneveld, R., Riser, S., Perry, M. J., and Strutton, P. G.: Observations of pigment and particle distributions in the western North Atlantic from an autonomous float and ocean color satellite, Limnol. Oceanogr., 53, 2112-2122, 2008.

Boyce, D. G., Lewis, M. R., and Worm, B.: Global phytoplankton decline over the past century, Nature, 466, 591-96, 2010.
Chacko, N.: Chlorophyll bloom in response to tropical cyclone Hudhud in the Bay of Bengal: Bio-Argo subsurface observations, Deep-Sea Res. Pt. I, 124, 66-72, 2017.

Chai, F., Johnson, K. S., Claustre, H., Xing, X., Wang, Y., Boss, E., Riser, S., Fennel, K., Oscar Schofield, O., and Sutton, A.: Monitoring ocean biogeochemistry with autonomous platforms, Nature Reviews Earth \& Environment, 1, 315-326, 2020.

Chang, Y., Liao, H. T., Lee, M. A., Chan, J. W., Shieh, W. J., Lee, K. T., Wang, G. H., and Lan, Y. C.: Multisatellite observation on upwelling after the passage of Typhoon Hai-Tang in the southern East China Sea, Geophys. Res. Lett., 35, L03612, 2008.

Chen, C. and Tang, D.: Eddy-feature phytoplankton bloom induced by a tropical cyclone in the South China Sea, Int. J. Remote Sens., 33, 7444-7457, 2012.

Chen, G, Xiu, P., and Chai, F.: Physical and biological controls on the summer chlorophyll bloom to the east of Vietnam, J. Oceanogr., 70, 323-328, 2014.

Chung, C., Gong, G., and Hung, C.: Effect of Typhoon Morakot on microphytoplankton population dynamics in the subtropical Northwest Pacific, Mar. Ecol. Prog. Ser., 448, 39-49, 2012.

Claustre, H., Bishop, J., Boss, E., Stewart, B., Berthon, J.-F., Coatanoan, C., Johnson, K., Lotiker, A., Ulloa, O., Perry, M. J., D’Ortenzio, F., D'andon, O. H. F., and Uitz, J.: Bio-optical profiling floats as new observational tools for biogeochemical and ecosystem studies, in: Proceedings of the "OceanObs'09: Sustained Ocean Observations and Information for Society" Conference, Venice, Italy, 21-25 September 2009, edited by: Hall, J., Harrison, D. E., and Stammer, D., ESA Publication WPP-306, 2010.

Cullen, J. J.: Subsurface Chlorophyll Maximum Layers: Enduring Enigma or Mystery Solved?, Annu. Rev. Mar. Sci., 7, 207-239, 2015.

Du, C., Liu, Z., Kao, S. J., and Dai, M.: Diapycnal fluxes of nutrients in an oligotrophic oceanic regime: the South China Sea, Geophys. Res. Lett., 44, 11510-11518, 2017.

Dunnavan, G. M. and Diercks, J. W.: An analysis of Super Typhoon Tip (October 1979), Mon. Weather Rev., 108, 1915-1923, 1980.

Elsner, J. B., Kossin, J. P., and Jagger, T. H.: The increasing intensity of the strongest tropical cyclones, Nature, 455, 92-95, 2008.

Emanuel, K. A.: Thermodynamic control of hurricane intensity, Nature, 401, 665-669, 1999.

Emanuel, K. A.: Increasing destructiveness of tropical cyclones over the past 30 years, Nature, 436, 686-688, 2005.

Frank, N. L. and Husain, S. A.: Deadliest tropical cyclone in history, B. Am. Meteorol. Soc., 52, 438-444, 1971.

Gierach, M. M., and Subrahmanyam, B.: Biophysical responses of the upper ocean to major Gulf of Mexico hurricanes in 2005, J. Geophys. Res., 113, C04029, 2008.

Glenn, S., Miles, T., Seroka, G., Xu, Y., Forney, R., Yu, F., Roarty, H., Schofield, O., and Kohut, J.: Stratified coastal ocean interactions with tropical cyclones, Nat. Commun., 7, 10887, 2016.

Gong, X., Jiang, W., Wang, L., Gao, H., Boss, E., Yao, X., Kao, S.-J., and Shi, J.: Analytical solution of the nitracline with the evolution of subsurface chlorophyll maximum in stratified water columns, Biogeosciences, 14, 2371-2386, https://doi.org/10.5194/bg-14-2371-2017, 2017.

Graff, J. R., Westberry, T. K., Milligan, A. J., Brown, M. B., Dall'Olmo, G., Van Dongen-Vogels, V., Reifela, K. M., and Behrenfelda, M. J: Analytical phytoplankton carbon measure- 
ments spanning diverse ecosystems, Deep-Sea Res. Pt. I, 102, 16-25, 2015.

Gray, W. M.: Global view of the origin of tropical disturbances and storms, Mon. Weather Rev., 96, 669-700, 1968.

Han, G., Ma, Z., and Chen, N.: Hurricane Igor impacts on the stratification and phytoplankton bloom over the Grand Banks, J. Marine Syst., 100-101, 19-25, 2012.

He, J. and Soden, B. J.: Anthropogenic weakening of the tropical circulation: the relative roles of direct $\mathrm{CO}_{2}$ forcing and sea surface temperature change, J. Climate, 28, 8728-8742, 2015.

Huang, S. M. and Oey, L. Y.: Right-side cooling and phytoplankton bloom in the wake of a tropical cyclone, J. Geophys. Res., 120, 5735-5748, 2015.

Jacob, S. D., Shay, L. K., Mariano, A. J., and Black, P. G.: The 3D oceanic mixed layer response to Hurricane Gilbert, J. Phys. Oceanogr., 30, 1407-1429, 2000.

Johnson, K. S. and Claustre, H.: Bringing Biogeochemistry into the Argo Age, Eos, 97, 11-15, 2016.

Kang, S.-W., Jun, K.-C., Park, K.-S., and Han, S.-D.: Storm surge hindcasting of Typhoon Maemi in Masan Bay, Korea, Mar. Geod., 32, 218-232, 2009.

Kara, A. B., Rochford, P. A., and Hurlburt, H. E.: An optimal definition for ocean mixed layer depth, J. Geophys. Res., 105, 16803, 2000.

Kossin, J. P.: A global slowdown of tropical-cyclone translation speed, Nature, 558, 104-107, 2018.

Letelier, R. M., Karl, D. M., Abbott, M. R., and Bidigare, R. R.: Light driven seasonal patterns of chlorophyll and nitrate in the lower euphotic zone of the North Pacific Subtropical Gyre, Limnol. Oceanogr., 49, 508-519, 2004.

Lin, I. I.: Typhoon-induced phytoplankton blooms and primary productivity increase in the western North Pacific subtropical ocean, J. Geophys. Res., 117, C03039, 2012.

Lin, I. I. and Chan, J. C.: Recent decrease in typhoon destructive potential and global warming implications, Nat. Commun., 6, 7182-7182, 2015.

Lin, I. I., Pun, I. F., and Wu, C. C.: Upper-ocean thermal structure and the western North Pacific category-5 typhoons. Part II: Dependence on translation speed, Mon. Weather Rev., 137, 37443757, 2009.

Lin, S., Zhang, W. Z., Shang, S. P., and Hong, H. S.: Ocean response to typhoons in the western North Pacific: Composite results from Argo data, Deep-Sea Res. Pt. I, 123, 62-74, 2017.

Liu, H., Hu, Z., Huang, L., Huang, H., Chen, Z., Song, X., Ke, Z., and Zhou, L.: Biological response to typhoon in northern South China Sea: A case study of "Koppu”, Cont. Shelf Res., 68, 123132, 2013

Locarnini, R. A., Mishonov, A. V., Baranova, O. K., Boyer, T. P., Zweng, M. M., Garcia, H. E., Reagan, J. R., Seidov, D., Weathers, K., Paver, C. R., and Smolyar, I.: World Ocean Atlas 2018, Vol. 1, Temperature, edited by: Mishonov, A., Technical Ed., NOAA Atlas NESDIS 81, 52 pp., 2018.

Mei, M., Lien, C. C., Lin, I. I., and Xie, S. P.: Tropical cycloneinduced ocean response: a comparative study of the South China Sea and Tropical Northwest Pacific, J. Climate, 28, 5952-5968, 2015.

Menkes, C. E., Lengaigne, M., Leìvy, M., Etheì, C., Bopp, L., Aumont, O., Vincent, E., Vialard, J., and Jullien, S.: Global impact of tropical cyclones on primary production, Global Biogeochem. Cy., 30, 767-786, 2016.

Mignot, A., Claustre, H., Uitz, J., Poteau, A., D’Ortenzio, F., and Xing, X.: Understanding the seasonal dynamics of phytoplankton biomass and the deep chlorophyll maximum in oligotrophic environments: A Bio-Argo float investigation, Global Biogeochem. Cy., 28, 856-876, 2014.

NASA Goddard Space Flight Center: Ocean Ecology Laboratory, Ocean Biology Processing Group, MODIS Aqua Chlorophyll Data, 2018 Reprocessing, NASA OB.DAAC, USA, https://doi.org/10.5067/AQUA/MODIS/L3B/CHL/2018 (last access: 31 March 2019), 2018.

NASA OBPG: MODIS Aqua Global Level 3 Mapped SST, Ver. 2019.0, PO.DAAC, CA, USA, https://doi.org/10.5067/MODSA1D4D9, last access: 31 March 2019.

Needham, H. F., Keim, B. D., and Sathiaraj, D.: A review of tropical cyclone-generated storm surges: global data sources, observations, and impacts, Rev. Geophys., 53, 545-591, 2015.

Pan, S., Shi, J., Gao, H., Guo, X., Yao, X., and Gong, X.: Contributions of physical and biogeochemical processes to phytoplankton biomass enhancement in the surface and subsurface layers during the passage of typhoon Damrey, J Geophys. Res.-Biogeo., 122, 212-229, 2017.

Platt, T.: Primary production of the ocean water column as a function of surface light intensity: algorithms for remote sensing, Deep-Sea Res. Pt. I, 33, 149-163, 1986.

Pothapakula, P. K., Osuri, K. K., Pattanayak, S., Mohanty, U. C., Sil, S., and Nadimpalli, R.: Observational perspective of SST changes during life cycle of tropical cyclones over Bay of Bengal, Nat. Hazards, 88, 1769-1787, 2017.

Price, J. F.: Upper ocean response to a hurricane, J. Phys. Oceanogr., 11, 153-175, 1981.

Price, J. F., Sanford, J. B., and Forristall, G. Z.: Forced stage responses to a moving hurricane, J. Phys. Oceanogr., 24, 233-260, 1994.

Sanford, T. B., Price, J. F., and Girton, J. B.: Upper ocean response to Hurricane Frances (2004) observed by profiling EM-APEX floats, J. Phys. Oceanogr., 41, 1041-1056, 2011.

Schmechtig, C., Thierry, V., and The Bio Argo Team: Argo quality control manual for biogeochemical data, https://doi.org/10.13155/40879, 2016.

Shang, S., Li, L., Sun, F., Wu, J., Hu, C., Chen, D., Ning, X., Qiu, Y., Zhang, C., and Shang, S.: Changes of temperature and biooptical properties in the South China Sea in response to Typhoon Lingling, 2001, Geophys. Res. Lett., 35, L10602, 2008.

Shibano, R., S., Yamanaka, Y., Okada, N., Chuda, T., Suzuki, S., and Niino, H.: Responses of marine ecosystem to typhoon passages in the western subtropical North Pacific, Geophys. Res. Lett., 38, L18608, 2011.

Sobel, A. H., Camargo, S. J., Hall, T. M., Lee, C. Y., Tippett, M. K., and Wing, A. A.: Human Influence on Tropical Cyclone Intensity, Science, 353, 242-246, 2016.

Sriver, R. L. and Huber, M.: Observational evidence for an ocean heat pump induced by tropical cyclones, Nature, 447, 577-580, 2007.

Sun, L., Yang, Y., Xian, T., Lu, Z., and Fu, Y.: Strong enhancement of chlorophyll a concentration by a weak typhoon, Mar. Ecol. Prog. Ser., 404, 39-50, 2010. 
Terzić, E., Lazzari, P., Organelli, E., Solidoro, C., Salon, S., D'Ortenzio, F., and Conan, P.: Merging bio-optical data from Biogeochemical-Argo floats and models in marine biogeochemistry, Biogeosciences, 16, 2527-2542, https://doi.org/10.5194/bg-16-2527-2019, 2019.

Vecchi, G. A. and Soden, B. J.: Effect of remote sea surface temperature change on tropical cyclone potential intensity, Nature, 450 , 1066-1070, 2007.

Wang, Y.: Composite of typhoon induced sea surface temperature and chlorophyll-a responses in the South China Sea, J. Geophys. Res.-Oceans, 125, e2020JC016243, 2020.

Webster, P. J., Holland, G. J., Curry, J. A., and Chang, H.: Changes in Tropical Cyclone Number, Duration, and Intensity in a Warming Environment, Science, 309, 1844-1846, 2005.

$\mathrm{Wu}, \mathrm{R}$. and $\mathrm{Li}, \mathrm{C}$.: Upper ocean responses to the passage of two sequential typhoons, Deep-Sea Res. Pt. I, 132, 68-79, 2018.

Xing, X., Wells, M. L., Chen, S., Lin, S., and Chai, F.: Enhanced Winter Carbon Export Observed by BGC-Argo in the Northwest Pacific Ocean, Geophys. Res. Lett., 47, e2020GL089847, 2020.

Yang, Y. J., Sun, L., Liu, Q., Xian, T., and Fu, Y.: The biophysical responses of the upper ocean to the typhoons Namtheun and Malou in 2004, Int. J. Remote Sens., 31, 4559-4568, 2010.

Ye, H. J., Sui, Y., Tang, D. L., and Afanasyev, Y. D.: A Subsurface Chlorophyll a Bloom Induced by Typhoon in the South China Sea, J. Marine Syst., 128, 138-145, 2013.
Zhao, H., Tang, D., and Wang, Y.: Comparison of phytoplankton blooms triggered by two typhoons with different intensities and translation speeds in the South China Sea, Mar. Ecol. Prog. Ser., 365, 57-65, 2008.

Zhao, H., Pan, J., Han, G., Devlin, A. T., Zhang, S., and Hou, Y.: Effect of a fast-moving tropical storm Washi on phytoplankton in the northwestern South China Sea, J. Geophys. Res., 122, 3404 3416, 2017.

Zhang, H., Wu, R., Chen, D., Liu, X., He, H., Tang, Y., Ke, D., Shen, Z., Li, J., Xie, J., Tian, D., Meng, J., Liu, F., Zhang, D., and Zhang, W.: Net modulation of upper ocean thermal structure by Typhoon Kalmaegi (2014), J. Geophys. Res., 122, 7154-7171, 2018.

Zheng, G. and Tang, D.: Offshore and nearshore chlorophyll increases induced by typhoon winds and subsequent terrestrial rainwater runoff, Mar. Ecol. Prog. Ser., 333, 61-74, 2007.

Zheng, Z.-W., Ho, C.-R., and Kuo, N.-J.: Importance of pre-existing oceanic conditions to upper ocean response induced by Super Typhoon Hai-Tang, Geophys. Res. Lett., 35, L20603, 2008.

Zhou, L., Tan, Y., Huang, L., Huang, J., Liu, H., and Lian, X.: Phytoplankton growth and microzooplankton grazing in the continental shelf area of northeastern South China Sea after Typhoon Fengshen, Cont. Shelf Res., 31, 1663-1671, 2011. 